\title{
Projetos de redução de emissões de gases de efeito estufa: desempenho e custos de
}

\section{transação}

\author{
Sara Gurfinkel Marques de Godoy
}

Com base na nova economia institucional, o foco da pesquisa aqui relatada foi identificar os custos de transação existentes nos projetos de Mecanismo de Desenvolvimento Limpo (MDL) e investigar se eles são barreiras para o desenvolvimento do projeto e se podem afetar a eficiência de projetos já implantados. Mais especificamente, foram analisadas as variáveis que afetam as diferenças entre as reduções de emissões estimadas nos projetos de MDL e as reduções realmente verificadas (sucesso de redução - SR), depois do projeto implantado e monitorado, verificando se os projetos agrícolas são mais ou menos eficientes. Em relação ao SR, a maior parte dos projetos não apresenta desempenho satisfatório. No entanto, em volume de reduções, a maior parte dos projetos cumpre mais do que $91 \%$ de SR. Os setores mundiais mais eficientes no Brasil são $\mathrm{N} 2 \mathrm{O}$ e troca de energia fóssil; os menos eficientes, os setores de agricultura e resíduos sólidos. Finalmente, concluiu-se na pesquisa que os custos de transação afetam o sucesso da redução de MDL, e os mais importantes são os custos ex ante, resultantes de problemas de falhas de informação e problemas de mensuração.

Palavras-chave: mecanismo de desenvolvimento limpo, nova economia institucional, economia institucional, Protocolo de Kyoto, custos de transação, mercado de carbono, crédito de carbono.

\section{INTRODUÇÃO}

A Convenção-Quadro das Nações Unidas sobre Mudança do Clima (CQNUMC), ocorrida em 1992, é um dos acordos mais relevantes da atualidade na busca pela redução dos gases de efeito estufa (GEE) na atmosfera. Desde então, reuniões subsequentes a esse primeiro encontro ocorrem anu-
Recebido em 28/maio/2012 Aprovado em 30/janeiro/2013

Sistema de Avaliação: Double Blind Review Editor Científico: Nicolau Reinhard

DOI: $10.5700 /$ rausp1090 
almente e, durante a terceira delas, o Protocolo de Kyoto foi criado para servir de base para os debates que perduram até os dias de hoje. Esse tratado determinou metas para os países desenvolvidos e economias em transição (denominados Anexo I da CQNUMC), a fim de reduzirem as emissões de GEE. Para facilitar o cumprimento dos objetivos determinados, o Protocolo de Kyoto criou três instrumentos de mercado chamados mecanismos de flexibilização; dentre eles, o que afeta diretamente os países em desenvolvimento é o Mecanismo de Desenvolvimento Limpo (MDL), por meio do qual as nações detentoras de metas podem cumprir seus compromissos de diminuição de emissões investindo em projetos de redução nos países em desenvolvimento. Em outras palavras, um país desenvolvido tem duas alternativas: investir em tecnologia mais eficiente em seu próprio país ou utilizar os mecanismos de flexibilização.

À luz da nova economia institucional, o objetivo principal neste trabalho é, a partir da apresentação de um panorama mundial de distribuição dos MDLs, analisar o desempenho dos projetos de redução de emissões de GEE implantados nos países em desenvolvimento. As hipóteses centrais que nortearam a investigação são descritas a seguir.

Hipótese 1 - O perfil de distribuição dos projetos de mecanismo de desenvolvimento limpo por sucesso de redução (desempenho dos projetos) é influenciado pelas especificidades dos projetos, como setor, escala, país, auditoria contratada, volume de emissões reduzidas e estimadas, metodologia utilizada no projeto e ano de emissão dos certificados de carbono.

Hipótese 2 - Projetos de redução de emissão relacionados à agricultura apresentam maior sucesso de redução de emissões.

Hipótese 3 - Os custos de transação exercem influência sobre as diferenças entre as reduções de emissão estimadas e as reduções de emissão efetivamente realizadas nos projetos de mecanismo de desenvolvimento limpo.

A pesquisa contou com dados secundários (análises de documentos oficiais e bibliografia pertinente ao tema e análise das teorias da economia institucional) e dados primários, por meio de entrevistas direcionadas aos players do mercado brasileiro que tiveram projetos de MDL implantados e certificados de carbono emitidos até março de 2009, totalizando 89 empresas. Desse universo, $46 \%$ responderam à pesquisa. Os dados quantitativos provêm de fontes disponíveis nos sites da Unep Risoe e United Nations Framework Convention on Climate Change (UNFCCC), e os qualitativos são resultados das análises e entrevistas.

\section{MECANISMO DE DESENVOLVIMENTO LIMPO E O MERCADO DE CRÉDITOS DE CARBONO}

A preocupação mundial com o aquecimento global abarca um novo enfoque em relação à natureza do problema ambiental, uma vez que há um efeito em cadeia, que se origina no meio ambiente, mas que se estende à economia e ao comportamento social em geral. Como consequência da convergência de interesses em diminuir as emissões dos GEE, as nações passaram a reunir-se com o intuito de discutir a respeito das implicações e das soluções para esse problema. Um importante acontecimento mundial, e um dos grandes propulsores do engajamento global na resolução dos males decorrentes da intensificação do efeito estufa, foi a Convenção-Quadro das Nações Unidas sobre Mudanças Climáticas (CQNUMC), estabelecida em 1992. Essa reunião teve como principal resultado a tomada de consciência sobre a necessidade de os países agirem conjuntamente, pois, caso contrário, seria muito difícil solucionar a questão do aquecimento global satisfatoriamente (CQNUMC, 2004a; CQNUMC, 2004b).

A primeira reunião da CQNUMC foi seguida de outros encontros anuais e, durante o terceiro deles, estabeleceu-se o Protocolo de Kyoto, em 1997, um tratado criado para dar maior sustentação às proposições inicialmente definidas, proporcionando garantia organizacional e estrutural à Convenção. Esses encontros anuais têm o propósito de melhor desenvolver as conclusões anteriormente acordadas e definir novas tomadas de decisões. Apesar de Kyoto ter sido estabelecido em 1997, esse documento serve ainda como base para as reuniões posteriores que ocorrem até os dias de hoje, e suas premissas permanecem, apesar de algumas modificações.

A criação do Protocolo somente foi possível porque diversos países com políticas e economias distintas chegaram a um acordo voluntário e consensual, o que significa dizer que todas as partes signatárias, sem exceção, concordaram com as regras estipuladas. $\mathrm{O}$ fato de ser um contrato voluntário significa que os países trabalham com a ideia de que os outros irão cumprir suas metas por meio de self-enforcing, e ser consensual significa que todos concordam com as regras determinadas. $\mathrm{O}$ problema é que, ao atender a essas duas condições, pode-se chegar a objetivos de redução não muito elevados (CHANDER e TULKENS, 2006).

O tratado de Kyoto é um tratado mundial com vinculação legal, segundo o qual os países industrializados (e demais pertencentes ao Anexo I da CQNUMC) deveriam reduzir suas emissões combinadas de gases de efeito estufa em torno de $5,2 \%$ em relação aos níveis de 1990 , no período compreendido entre 2008 e 2012, primeiro período de Kyoto. Esse documento somente entraria em vigor depois de ratificado por 55 países do Anexo I, que representassem pelo menos 55\% das emissões de GEE ocorridas no ano de 1990. CHADWICK (2006) aponta Kyoto como o mais ambicioso sistema de controle de poluição jamais acontecido até sua adoção. 
Reuniões anuais continuaram acontecendo, e em 2012, em Doha, foi acordado o segundo período de compromisso de Kyoto, de janeiro de 2013 a dezembro 2020, incluindo novos compromissos para as Partes do Anexo I, que se comprometeram em reduzir as emissões de GEE em pelo menos 18\% abaixo dos níveis de 1990.

O Protocolo é um documento que apresenta uma linguagem de natureza técnica baseada no entendimento jurídico internacional. Trata-se de um acordo de difícil concordância de ideias entre as partes negociantes. $O$ documento resultante não é totalmente objetivo e em alguns pontos caracteriza-se pela ausência de definições claras e unívocas. As dúvidas em relação às informações são alvo constante de críticas e discussões, que ocorrem desde sua criação até os dias de hoje. No entanto, é de interesse geral que atualizações e melhorias sejam feitas para maior aceitação e, por essa razão, as discussões ocorridas nas reuniões posteriores à criação do Protocolo continuam a acontecer, numa tentativa de adaptação à realidade e ao interesse da maioria.

\subsection{Princípios do Protocolo de Kyoto}

Para facilitar o cumprimento das metas de redução, o Protocolo de Kyoto criou instrumentos de mercado chamados mecanismos de flexibilização, a implementação conjunta, o comércio de emissões e o Mecanismo de Desenvolvimento Limpo (MDL). Os três instrumentos permitem a criação e o desenvolvimento do mercado de carbono.

A implementação conjunta consiste em que os países industrializados compensem suas emissões participando de projetos e sumidouros em outros países do Anexo I. O comércio de emissões permite que países desenvolvidos negociem entre si quotas de emissão acordadas em Kyoto (CQNUMC, 2004a).

Finalmente, o mecanismo que afeta diretamente os países em desenvolvimento é o mecanismo de desenvolvimento limpo, por meio do qual os países industrializados podem cumprir seus compromissos de redução investindo em projetos que evitem as emissões de gases de efeito estufa nos países em desenvolvimento.

Em outras palavras, um país desenvolvido tem duas alternativas: investir em tecnologia mais eficiente em seu próprio país, ou utilizar os mecanismos de flexibilização. Como consequência da implantação de projetos de redução no âmbito de Kyoto, surgiram os certificados de carbono, comercializáveis e equivalentes ao volume de redução das emissões dos GEE efetivamente alcançada depois da implantação de um projeto.

O mercado de créditos de carbono abrange a comercialização de certificados ${ }^{(1)}$ resultantes da adoção de Kyoto, além de outros programas de redução como os de licenças para poluir. Existem diferentes tipos de comércio de certificados, muitos deles voluntários e sem padronização. No entanto, em geral seguem algumas linhas básicas comuns a todos, embasadas em conceitos teóricos pensados muito antes da criação do
Protocolo de Kyoto. Assim sendo, não há um único mercado de carbono, definido por uma única commodity, por apenas um contrato. $\mathrm{O}$ que é comumente chamado de mercado de carbono é, assim, uma coleção de diversas transações, por meio das quais volumes de reduções de emissões de GEE são comercializados, diferenciando-se em relação a tamanho, formato e regulamentação. Essas transações podem ser também separadas em Kyoto compliance e non-Kyoto compliance, que seriam os créditos de carbono que obedecem aos parâmetros impostos pelo Protocolo ou não. As informações referentes a esse mercado são limitadas e, principalmente, de difícil mensuração, pois não há uma câmara central de compensação para as transações, além de não ser obrigatória a publicação dos preços e negociações (GODOY, 2009).

\section{ECONOMIA INSTITUCIONAL, NOVA ECONOMIA INSTITUCIONAL E O MERCADO DE CARBONO}

A discussão sobre as medidas para lidar com as mudanças climáticas incorre na definição de qual a solução mais eficiente para a degradação de recursos naturais, rotulada como uma externalidade negativa. Externalidades negativas ou deseconomias de aglomeração surgem quando as atividades das empresas não geram somente resultados positivos, mas também negativos a outros, em consequência de uma definição imprecisa dos direitos de propriedade privados. $\mathrm{O}$ ar é um bem público, um recurso de propriedade comum a toda sociedade, de difícil mensuração e transacionalização, e o mercado de carbono surge como uma tentativa de definir os direitos de propriedade sobre a poluição atmosférica, internalizando essa externalidade negativa (PINDYCK e RUBINFELD, 1999).

Pigou (1920) apresenta como solução para as externalidades negativas a criação de taxas (taxa pigouviana) em valor equivalente ao custo (benefício) da externalidade gerada. Tal solução sugere a valoração econômica da degradação e, por meio da intervenção do Estado, adota o sistema de taxação.

Nos anos 1960, o prêmio Nobel Ronald Coase, em seu artigo "The problem of social cost", propôs uma nova forma de analisar essa questão (COASE, 1960). Ele considera que as soluções privadas, em geral, envolvem custos menores, isso porque, caso não haja custos de transação $(\mathrm{CT})$, os resultados não seriam afetados pela ação do Estado. A partir dessa lógica, nasce a linha teórica denominada de nova economia institucional, que tem como um de seus entendimentos que o Estado deve criar condições, por meio de definição de direitos de propriedade, para que os agentes econômicos negociem livremente no mercado os chamados bens ambientais, como a redução da poluição atmosférica. O comércio de carbono traz em sua essência a lógica apresentada por Coase, uma vez que viabiliza um instrumento, que visa à apropriação de um bem livre ${ }^{(2)}$ a partir de comércio de certificados de redução (MUELLER, 2002).

No mercado de carbono, transações acontecem podendo emergir custos de transação, nesse sentido é importante o en- 
tendimento dos pressupostos das teorias dos CT. Os custos de transação são os recursos alocados para coordenar a produção do bem, como a elaboração de contratos, a obtenção de novas informações sobre o produto e concorrentes, a barganha, a condução das negociações e o monitoramento do processo. North (1990) ainda diferencia os custos de transação dos de transformação, pois estes últimos são os custos decorrentes da modificação do insumo em produto, e custos de produção, a soma dos dois custos (WILLIAMSON, 1985; NORTH, 1994; ZYLBERSZTAJN e SZTAJN, 2002).

Esses custos podem ser divididos em custos de transação ex ante e ex post. Os primeiros são os relativos às negociações prévias consequentes das definições das características do objeto transacionado, que abrangem os custos necessários à coleta de informações, à negociação, à elaboração de contratos e de salvaguardas contratuais. Os custos ex post são os possíveis custos de adaptações às cláusulas inicialmente acordadas, como custos de monitoramento, administrativos, e custos de rompimento contratual (WILLIAMSON, 1993, apud ZYLBERSZTAJN, 1995; WILLIAMSON, 1993).

Os custos de transação estão presentes em cada etapa do processo de implantação de um projeto de mecanismo de desenvolvimento limpo, tais como na elaboração do contrato inicial de apresentação do projeto; na validação; na aprovação; no registro no Comitê Executivo do $\mathrm{MDL}^{(3)}$; no processo de monitoramento do projeto; na certificação; na emissão dos certificados de emissões reduzidas e na definição da metodologia a ser utilizada nos projetos. Custos muito elevados podem ser um entrave à entrada de novas empresas interessadas em implantar projetos de MDL, sendo interesse deste trabalho identificar sua relevância.

\section{SUCESSO DE REDUÇÃO E PANORAMA DOS PROJETOS DE MECANISMO DE DESENVOLVIMENTO LIMPO MUNDIAIS}

O proponente deve entrar com uma documentação específica (DCP - Documento de Concepção do Projeto) junto ao Comitê Executivo do MDL para ter seu projeto aprovado. $\mathrm{O}$ documento deve contemplar todas as características da atividade pretendida, com a descrição do projeto bastante detalhada, incluindo dados sobre projeções de reduções de emissões que intenciona alcançar depois de sua implantação (Quadro 1). Os tipos de informações necessárias são determinados pela UNFCCC, e os proponentes são obrigados a seguir o padrão específico de preenchimento do documento. Esse processo de levantamento de dados está sujeito a falhas, uma vez que se trabalha com estimativas do que será o projeto.

O processo de análise de viabilidade dos projetos é bastante rigoroso e, depois de o MDL ser finalmente aprovado e estar efetivamente em funcionamento, é necessário verificar se as reduções de emissões estão realmente ocorrendo de acordo com as estimativas inicialmente propostas. A partir dessa contrapo-

\section{Quadro 1}

\section{Exemplos de Informações Necessárias para Serem Preenchidas no Documento de Concepção do Projeto}

Informações do Documento de Concepção do Projeto (DCP)

Metodologia $\left.{ }^{*}\right)$ de cálculo e de monitoramento do projeto (mostrando como irá verificar se as reduções propostas estão sendo cumpridas)

Análise de impactos ambientais

Local de implantação do projeto

Tecnologias a serem utilizadas

Setor

Escala do projeto

Anos de redução

Utilização ou não de consultoria

Nota: (*) Metodologias são métodos de cálculo que as empresas utilizam para demonstrar as reduções de emissões, se organizar, implantar a tecnologia adequada e, também, definir o monitoramento das reduções. O conjunto de informações disponíveis que determinam uma dada metodologia é definido por códigos, tais como AM01, ACM21. Inclui o setor do projeto, gás a ser reduzido, tamanho, entre outras especificidades do projeto.

sição de emissões projetadas e efetivas é que os certificados de carbono serão emitidos.

O objetivo das análises dos dados mundiais dos projetos de MDL neste trabalho é identificar a ocorrência de discrepâncias entre as reduções realizadas e projetadas. Para identificar essas diferenças define-se Sucesso de Redução (SR) (desempenho) como a relação entre as reduções de emissões efetivas e estimadas. Assim, quanto mais próximo de $100 \%$, maior o cumprimento das projeções; quanto mais afastado desse valor, maiores os erros de estimativas. Num segundo momento, com o intuito de verificar qual o papel dos custos de transação nos $\mathrm{SR}$, os projetos brasileiros são investigados mais a fundo no tópico seguinte.

O levantamento de dados para o estudo sobre os MDLs mundiais inclui os projetos de mecanismo de desenvolvimento limpo que tiveram certificado de redução de emissões emitidas até março de 2009. O universo de análise global inclui 33 países e 472 projetos de $\mathrm{MDL}^{(4)}$. As análises levam em conta diversas variáveis (Quadro 2), e a consolidação das informações é separada por volume de reduções e por número de projetos. Isso se faz necessário, pois o perfil de distribuição dos projetos difere quando analisados esses dois fatores, podendo ocorrer, por exemplo, de apenas um projeto ter mais volume de redução do que dezenas de outros pertencentes a outro setor. 


\section{Quadro 2}

\section{Variáveis Consideradas nas Análises dos Perfis dos Projetos}

\begin{tabular}{|c|}
\hline \multicolumn{1}{|c|}{ Variáveis Analisadas $^{\left({ }^{*}\right)}$} \\
Metodologia utilizada $^{\text {País }}$ \\
\hline Ano de emissão dos certificados \\
\hline Contratação ou não de auditoria \\
\hline Setor do projeto \\
\hline
\end{tabular}

Nota: * As análises dos dados primários e secundários são baseadas nas informações tabuladas e distribuídas em 11 tabelas, com análises de cada variável comparada com o SR. Para detalhes dessa tabulação, consultar Godoy (2010).

Os principais setores analisados foram:

- Agricultura - recuperação e destruição de metano proveniente de esterco e resíduos de atividades agrícolas ou agroindustriais que se decomporiam anaerobicamente na ausência da atividade do projeto.

- Biomassa - projetos que visem à geração de energia por meio de utilização de biomassa ou outra matéria orgânica que de outra forma teria sido abandonada até decompor-se em condições anaeróbicas.

- Geotérmica - atividades relacionadas com geração de energia geotérmica, em substituição a atividades mais poluentes.

- Redução de HFCs - projetos que buscam a redução de gases halocarbonos e hexafluoretos.
- Resíduos sólidos - tratamento aeróbico de águas residuais ou lodo por sistemas anaeróbicos com recuperação e combustão de metano, como tratamento de esgotos, compostagem, construção de aterros sanitários.

- Redução de N2O - projetos industriais que buscam a redução de gases N2O.

- Energia solar - projetos de substituição de energia fóssil por renovável, por meio de aproveitamento de energia solar.

- Energia eólica - instalação de projetos que utilizam o vento como fonte de energia em substituição a energias mais poluentes.

- Hidrelétrica - atividades de projetos de geração de energia renovável conectada à rede por meio de usinas hidrelétricas.

Como resultado das análises, $78 \%$ do mercado de MDL mundial pertence a três países: Índia, 37\%; China, 22\%; Brasil, $19 \%$. Em relação ao volume de redução de emissões, verifica-se uma mudança nesse ranking principalmente em virtude do alto volume de alguns projetos existentes na Coreia do Sul (China, 43\%; Índia, 23\%; Coreia do Sul, 14\%; Brasil, 11\%) (Gráfico 1). Os setores mais relevantes em termos de volume de redução de emissões são projetos de HFC e N2O (representando $\mathbf{8 4 \%}$ do mercado), e em número de projetos biomassa, energia hidrelétrica e eólica (representando $\mathbf{5 9 \%}$ do mercado). Os projetos agrícolas têm uma participação pequena em volume total (1\%), mas, em termos de volume, existem 38 projetos, representando $8 \%$ do total mundial (Gráfico 2).

Outra conclusão é de que a maioria dos projetos não cumpre as reduções inicialmente estimadas. Esse perfil altera-se totalmente quando analisado o volume de emissões reduzidas, uma vez que $\mathbf{8 5 \%}$ do volume alcança no mínimo 91\% de SR (Gráfico 3). Essa mudança de perfil ocorre principalmente em consequência da existência de poucos projetos redutores

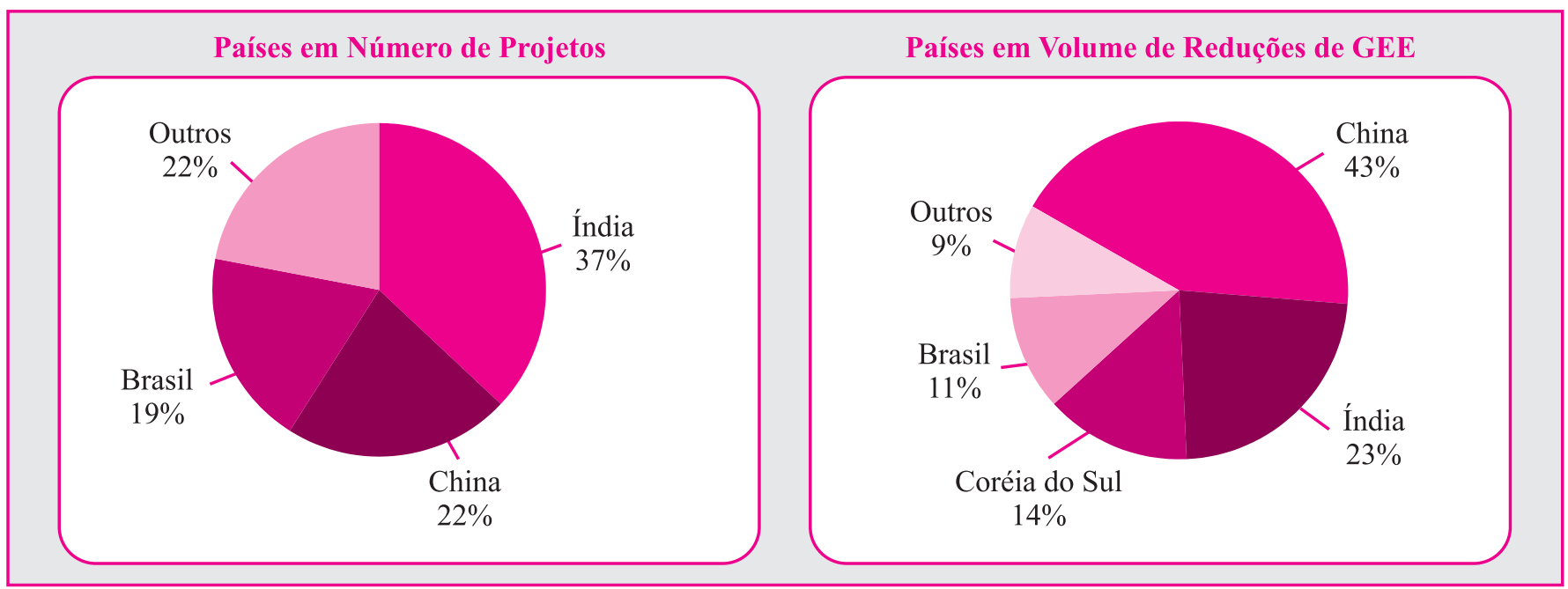

Gráfico 1: Países em Número de Projetos e Países em Volume de Redução de Emissões 


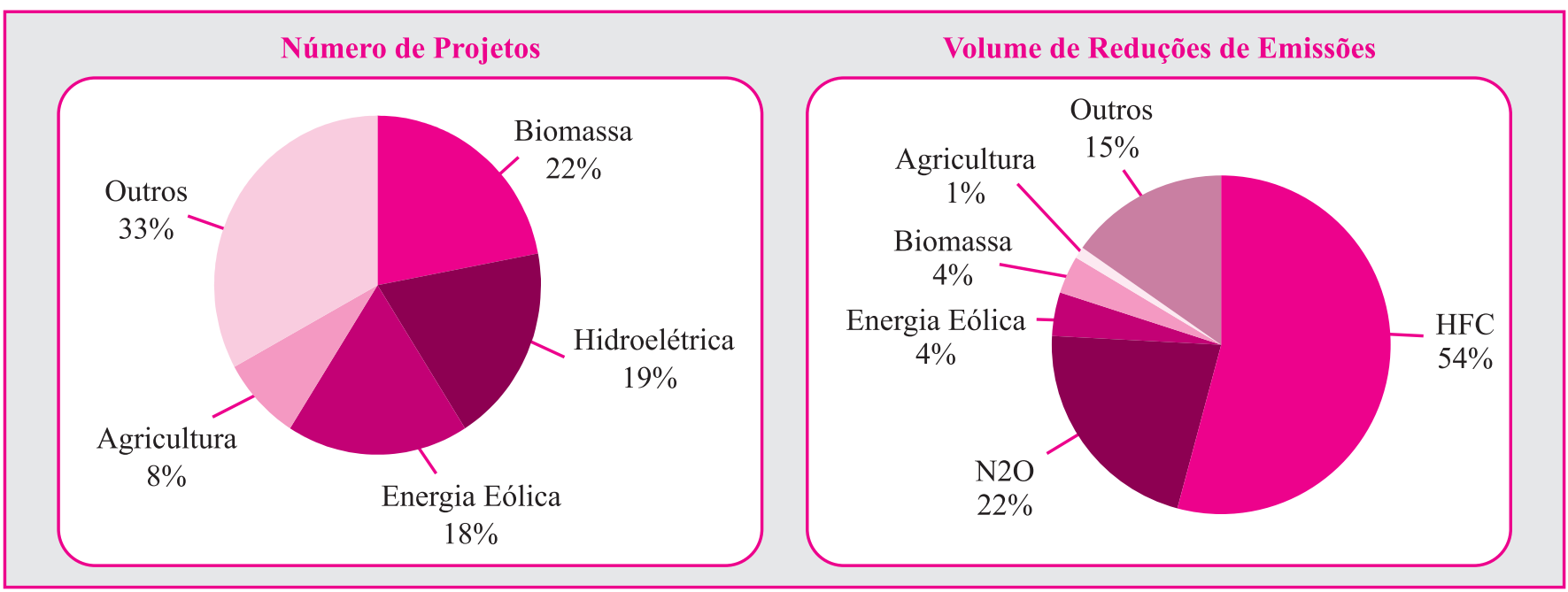

Gráfico 2: Setores de Projetos por Número de Projetos e Volume de Reduções

de gases $\mathrm{N} 2 \mathrm{O}$ e de $\mathrm{HFC}$, mas com alto volume de reduções, respondendo por $\mathbf{7 6} \%$ de todo o volume de reduções mundiais. Esses dois setores apresentam alto potencial de redução de emissões, pois trata-se de gases muito poluentes. Concluindo, projetos de redução de HFCs e N2O projetaram suas reduções de GEE muito acima das expectativas inicialmente propostas.

Em relação aos setores, os projetos com SR inferiores a 90\% são nesta ordem: projetos de resíduos sólidos, agricultura e troca de energia fóssil. Quando analisados os números de projetos, os com mais projetos SR abaixo de 90\% são: resíduos sólidos, agricultura e energia eólica. Cabe ressaltar que os demais setores também têm grandes percentuais de seus projetos em intervalos de baixo SR (Gráfico 4).

A maioria dos projetos agrícolas cumpre menos do que $90 \%$ de SR, demonstrando a baixa eficiência desses setores em termos de projeção de emissões. Quando analisados números de projetos, a concentração abaixo de $90 \%$ é ainda maior (Gráficos 5 e 6).

Em relação aos projetos brasileiros, $\mathbf{5 2 \%}$ dos MDLs cumprem menos do que $90 \%$ de SR; em relação ao volume de reduções, caem para $\mathbf{2 6 \%}$ em razão de seu projeto de N2O de alto volume de redução e com cumprimento acima de $110 \%$, o que eleva a média de cumprimento de redução. Dentre os seto-

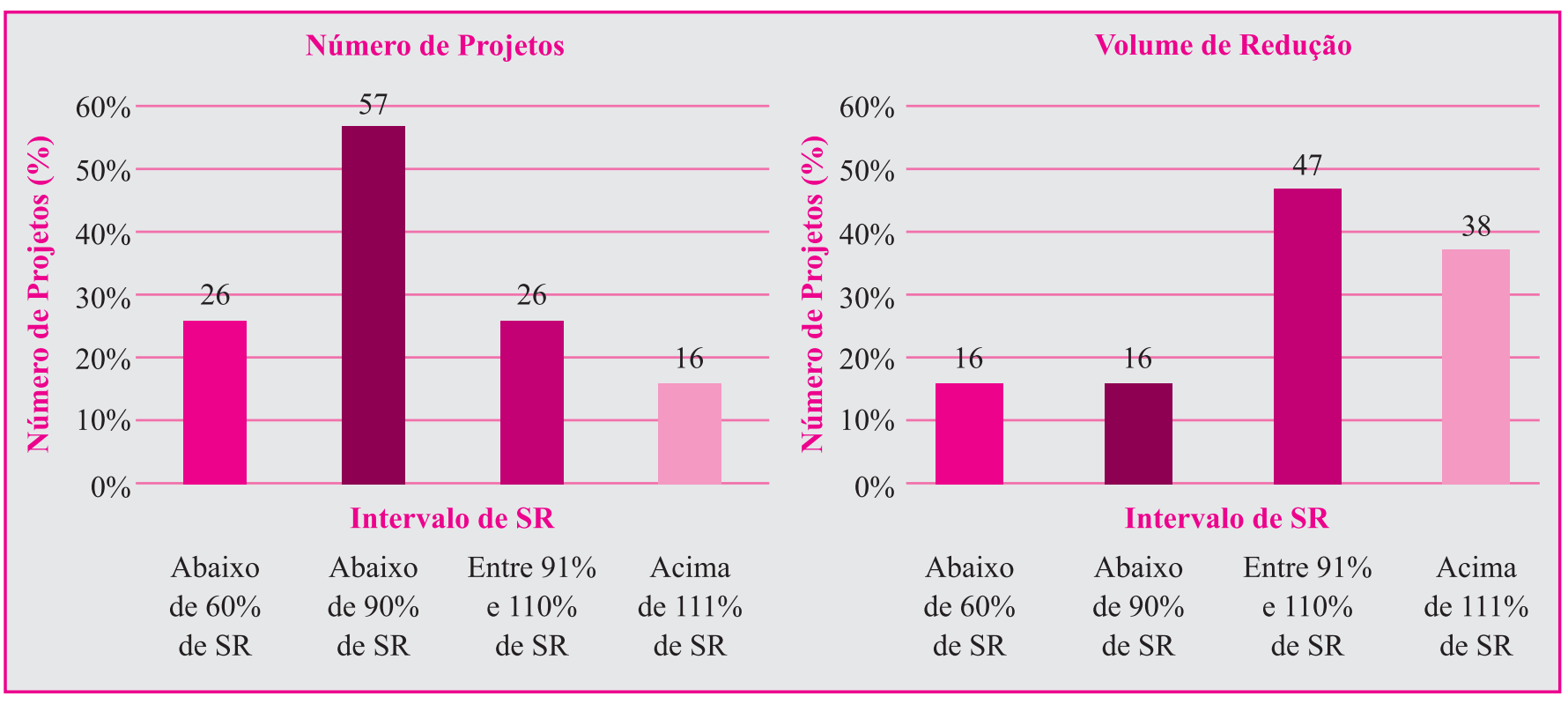

Gráfico 3: Distribuição dos Projetos de MDL por Número e por Volume de Redução de Emissões por Sucesso de Redução (SR) 


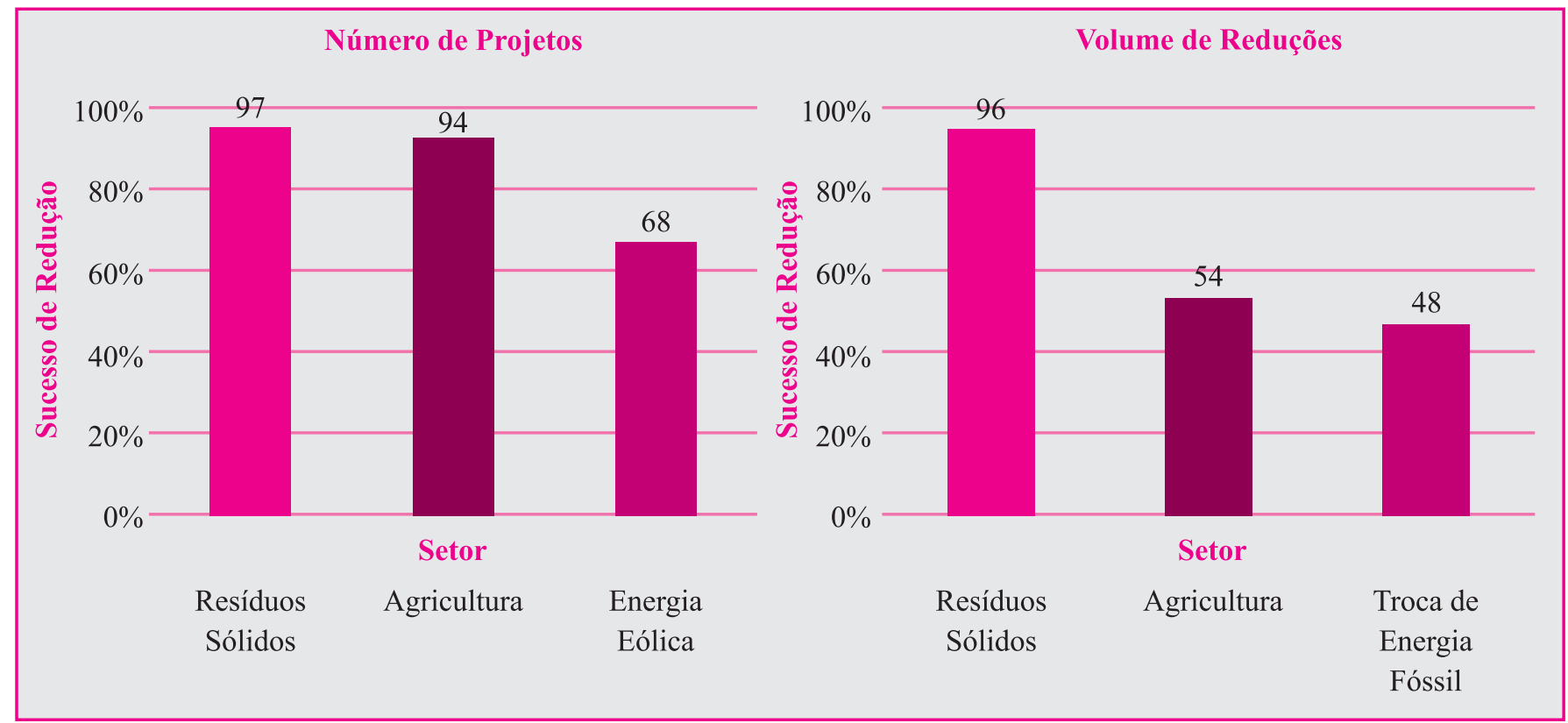

Gráfico 4: Setores mais Relevantes em Número de Projetos e em Volume de Redução e SR Inferiores a 90\% (Porcentagem de seus Totais)

res relevantes com maior concentração em SR abaixo de 90\% estão agricultura, resíduos sólidos e biomassa. Esses setores têm distribuição semelhante aos demais países, exceto projetos agrícolas, que é pior no Brasil, pois todos estão abaixo de $90 \%$ de SR. Cabe ressaltar que o Brasil é o país no mundo que tem maior número de projetos com SR abaixo de $20 \%$, em razão de projetos de agricultura e resíduos sólidos.
Assim, o setor no qual o projeto de MDL é desenvolvido tem grande influência na distribuição do sucesso de redução, tanto em relação ao volume de redução de emissões, quanto em número de projetos.

Um fato relevante é que a concentração dos SR pode alterar-se, dependendo da metodologia utilizada, ou seja, um mesmo tipo de projeto que utiliza uma dada metodologia apresenta um

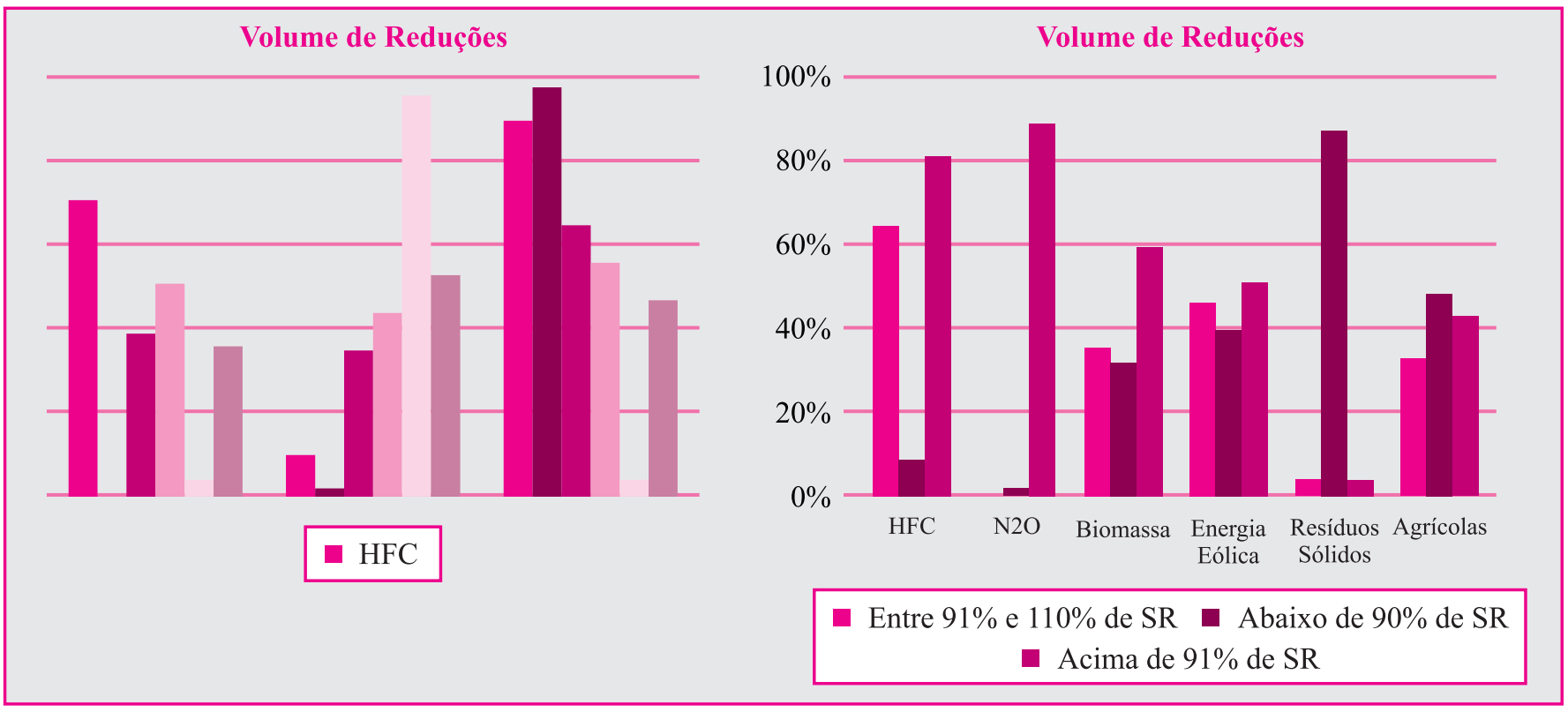

Gráfico 5: Setores dos Projetos por Intervalo de Sucesso de Redução (Volume de Redução) 


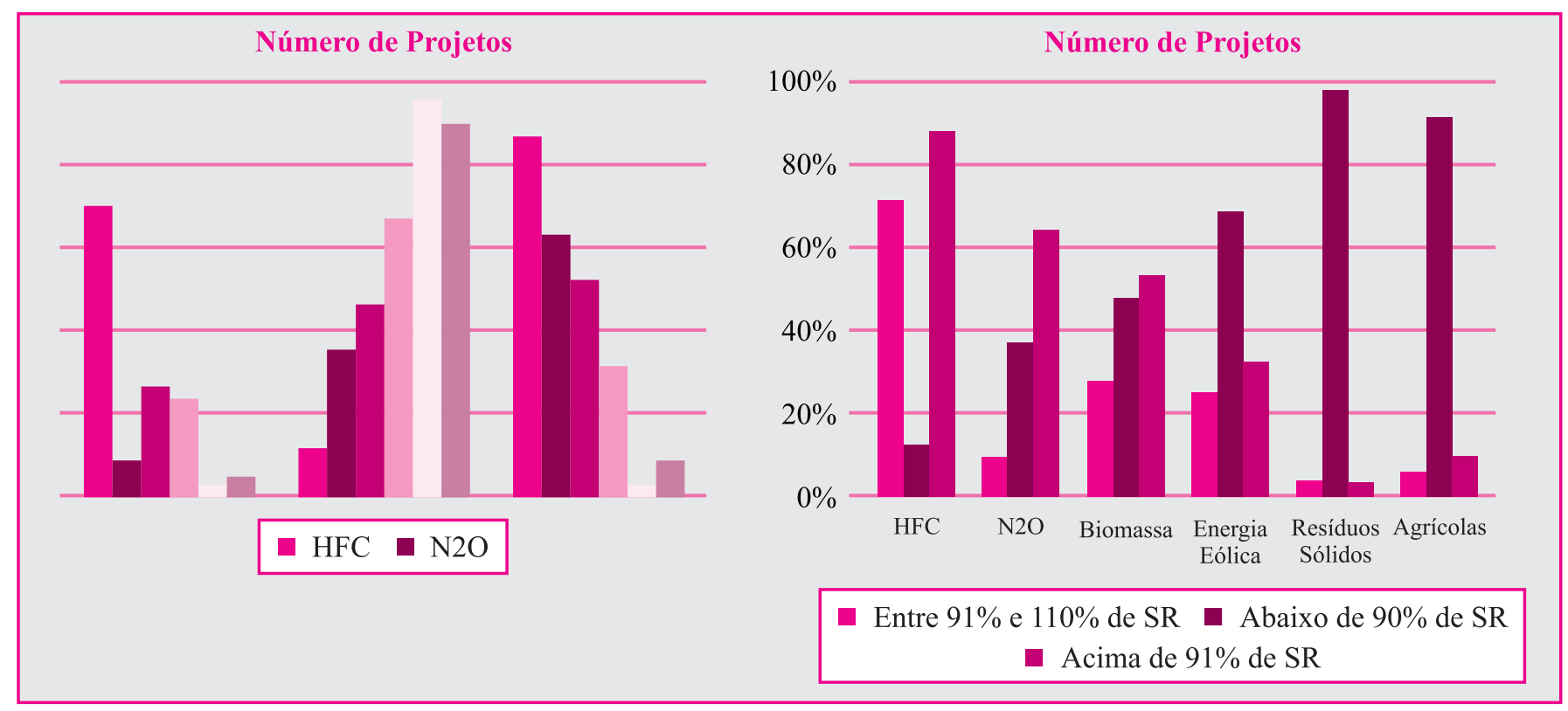

Gráfico 6: Setores dos Projetos por Intervalo de Sucesso de Redução (Número de Projetos)

perfil de distribuição de SR, e o mesmo setor com outra metodologia pode ter outro perfil de cumprimento das reduções. Essas diferenças também podem ser observadas quando comparados os países, pois um mesmo tipo de projeto ou metodologia tem perfil diferente conforme o país que o adota, conclusão advogada nos pressupostos da economia institucional, que concorda com o fato de que as particularidades locais podem afetar o resultado econômico.

Quanto às diferenças constatadas nos perfis de distribuição dos SR por total de volume de reduções, estimados e setores de projetos, não é possível afirmar que se deram em razão dos custos de transação existentes nos projetos, pois podem ser resultado tanto de problemas de organização, ou de má definição das instituições, assimetria de informações, quanto dos demais custos existentes.

No entanto, em se tratando de metodologias, é possível afirmar com mais acuidade que abrangem problemas de custos de transação. Uma metodologia específica oferece uma série de procedimentos, fórmulas de cálculo e outras informações referentes à estruturação do MDL. Além das definições de como se dará a estimação das reduções dos GEE e de como se comportam as emissões dos gases antes da implantação do projeto, faz parte do escopo da metodologia determinar os detalhes e as especificidades do monitoramento das reduções que porventura ocorram decorrentes da implantação do MDL. Para definir esses procedimentos, é imprescindível reunir informações sobre atividades semelhantes já existentes, detalhes sobre o setor, além de estabelecer como serão as atividades adequadas para promover o monitoramento do projeto. Assim, qualquer falha de informações em relação à concorrência, ou aos processos necessários para o monitoramento, pode prejudicar o projeto e configura problemas específicos de custos de transação.

Outro exemplo de variável que afeta o perfil dos SR são os anos em que os certificados são emitidos. Com base nas análises conclui-se que, conforme o período observado de emissão dos certificados de carbono, a distribuição dos SR se altera. No entanto, não é possível concluir se esses dados são influenciados somente pelos custos de transação, ou por outro motivo que, com os dados disponíveis, não foi possível constatar.

Já a análise do perfil dos projetos de acordo com as auditorias adotadas demonstra que, conforme a empresa contratada, o perfil do SR se modifica, e o processo de verificação incorre diretamente em custos de transação. Com a ideia de verificar se as reduções estão realmente ocorrendo, são contratadas empresas de auditoria responsáveis pela constatação da veracidade das reduções. A maneira como essas organizações executam suas auditorias segue um padrão de medidas ditado pela UNFCCC, mas existem as particularidades de comportamento de cada empresa e por isso é possível observar que há diferenças na distribuição dos projetos por SR, dependendo da auditoria utilizada. Além desse fato, o perfil dos MDLs também se altera, quando analisada a influência que uma mesma auditoria exerce sobre a distribuição dos projetos em diferentes países, o que ressalta que as particularidades locais podem afetar o comportamento dos projetos, uma clara evidência da relevância dos custos de transação no sucesso dos projetos.

Concluindo, pode-se dizer que as informações analisadas neste tópico sugeriram que os custos de transação influenciam no perfil do SR. No entanto, apenas com os dados mundiais disponíveis não foi possível determinar o sentido específico 
dessa influência; as análises serão aprofundadas no tópico subsequente.

\section{CUSTOS DE TRANSAÇÃO E OS PROJETOS DE REDUÇÃO DE EMISSÕES BRASILEIROS (MDL)}

Este tópico é desenvolvido para mostrar as razões que poderiam afetar o sucesso de redução de projetos de MDL no Brasil, identificando se os custos de transação poderiam influenciar essas diferenças. Somando-se a isso, as análises são focadas na identificação de se os custos de transação são barreiras para desenvolver um projeto de MDL. A análise dos custos de transação busca levantar a importância não somente dos valores financeiros, mas também daqueles custos decorrentes de falta de informação, negociação e elaboração de contratos, metodologias de cálculos erradas e relação com intemedíários. Tendo em vista as dificuldades de mensurar esses dados caracterizados pela subjetividade e a não possibilidade de quantificação, neste artigo lança-se mão de análise de entrevistas com organizações mergulhadas no processo de MDL, os implantadores de projetos.

A pesquisa também contou com a colaboração de formadores de opinião, profissionais ligados aos projetos de MDL, tanto direta quanto indiretamente. Foram entrevistados: um consultor de MDL, um professor consultor de projetos de energia e MDL, um especialista de MDL e um profissional do mercado financeiro ligado à área de carbono. As informações levantadas com esses entrevistados serviram para aprofundar o conhecimento do mercado, além de melhorar a elaboração do questionário.

O universo pesquisado equivale às 89 empresas com projetos de MDL implantados no Brasil e que já tiveram certificados emitidos até março de 2009. Dos 89 projetos de MDL, distribuídos em 11 setores, 41 responderam à pesquisa, correspondendo a $46 \%$ de respostas sobre o total de questionários enviados.

As conclusões sobre os projetos brasileiros partiram das análises dos projetos mundiais, que serviram como ponto de partida para o aprofundamento dos entendimentos e serviram como base para a construção dos questionários. A pesquisa foi dividida em quatro questões de múltipla escolha e uma descritiva.

A primeira questão ("Classificar os motivos que, em sua opinião, influenciam a decisão de as empresas implantarem um MDL") tem o objetivo de identificar os interesses das empresas em implantar um projeto (Tabela 1). A princípio, os projetos de MDL têm intuito meramente ambiental de diminuir emissões, mas podem assumir uma dimensão maior, uma vez que são projetos que resultam em alterações tecnológicas, em recursos financeiros com a venda de certificados e até mesmo na possibilidade de aumentar a visibilidade da empresa no mercado.

A segunda questão ("Em geral, os projetos de MDL brasileiros e nos outros países apresentam diferenças entre as reduções de emissões propostas nos DCPs e as observadas depois do monitoramento/certificação. Em sua opinião, qual a contribuição das variáveis a seguir para explicar as diferenças em seu projeto de MDL, caso ocorram?") foi formulada para determinar quais as possíveis razões que ocasionam as diferenças entre as reduções de emissão propostas inicialmente nos projetos de MDL e as que realmente ocorreram, depois da verificação das diminuições dos GEE (Tabela 2). A implantação de um MDL requer que o proponente passe por uma série de etapas e, influenciado por diversas organizações, tenha de obedecer a regras específicas e gerais. Com base nas respostas, as conclusões da segunda questão buscam identificar e verificar se os custos de transação exercem papel relevante nas diferenças de SR constatadas nos projetos.

A terceira questão ("Em todo o processo de implantação do MDL, em geral, as empresas encontram barreiras e/ou dificuldades em relação a:") tem o interesse de levantar em que etapa do ciclo do MDL os entrevistados encontraram barreiras e dificuldades (Tabela 3).

Reforçando os questionamentos das perguntas anteriores, a questão 4 ("Em sua opinião, em que grau (de 0 a 5) as variáveis a seguir contribuíram para impedir que uma empresa implante um novo projeto de MDL:") e a questão descritiva 5 ("O que poderia ser modificado para melhorar o processo de MDL, ou para que mais empresas façam projetos de MDL no Brasil?") foram formuladas para novamente traçar um perfil de comportamento dos proponentes de MDL, levantando suas dificuldades e opiniões sobre todo o processo de implantação de um projeto (Tabela 4).

Como descrito no tópico 2 deste trabalho, os custos de transação podem ser subdivididos em ex ante e ex post. As alternativas apresentadas nos questionários enviados aos entrevistados podem ser relatadas conforme esse entendimento, sendo possível separá-las como no Quadro 3.

Em relação ao Quadro 3, pode-se concluir que os custos de transação que permeiam um projeto de MDL podem ser separados em custos ex ante, anteriores à implantação de um projeto, e custos ex post, os que podem ocorrer depois de implantado o projeto.

Os custos ex ante podem, ainda, ser separados em:

- custos de informação - aqueles decorrentes da procura por informação, ou por falta e falhas de informação, que pode levar a escolha errada de uma dada metodologia ou tecnologia, bem como afetar a eficiência das organizações contratadas;

- custos de intermediários - correspodem aos gastos com as organizações que intermedeiam o processo do MDL e são responsáveis pela finalização de cada estágio antes da aprovação final e da implantação do projeto. Ou a contratação de uma consultoria, que não é obrigatória, mas muitas vezes ocorre com a intenção de facilitar a aprovação e implantação de um projeto;

- outros custos - como aqueles decorrentes de tempo gasto entre a preparação do projeto e depois de ele estar efetivamente em andamento; 
Tabela 1

\section{Alternativas Referentes à Primeira Questão do Questionário e Percentual de Respostas por Grau de Contribuição em Cada Variável}

\begin{tabular}{|c|c|c|c|c|c|c|c|c|c|}
\hline \multirow{3}{*}{ Perguntas } & \multicolumn{8}{|c|}{ Grau de Contribuição } & \multirow{3}{*}{$\begin{array}{c}\text { Total } \\
\text { Balizado }\end{array}$} \\
\hline & $\begin{array}{l}\text { Muito } \\
\text { (A) }\end{array}$ & $\begin{array}{l}\text { Não Muito } \\
\text { (B) }\end{array}$ & $A+B$ & $\begin{array}{l}\text { Pouco } \\
\text { (C) }\end{array}$ & $A+B+C$ & $\begin{array}{c}\text { Muito } \\
\text { Pouco (D) }\end{array}$ & $\begin{array}{c}\text { Nada } \\
(\mathrm{E})\end{array}$ & $D+E$ & \\
\hline & 1 & 2 & & 3 & & 4 & 5 & & \\
\hline \multirow{2}{*}{$\begin{array}{l}\text { Venda dos CERs (Certificados de } \\
\text { Emissão Reduzidas) }\end{array}$} & $65 \%$ & $13 \%$ & $78 \%$ & $15 \%$ & $93 \%$ & $8 \%$ & $0 \%$ & $8 \%$ & \\
\hline & 0,7 & 0,3 & 0,9 & 0,5 & 1,4 & 0,3 & - & 0,3 & 1,7 \\
\hline \multirow{2}{*}{ Marketing/Visibilidade da empresa } & $49 \%$ & $22 \%$ & $71 \%$ & $17 \%$ & $88 \%$ & $10 \%$ & $2 \%$ & $12 \%$ & \\
\hline & 0,5 & 0,4 & 0,9 & 0,5 & 1,4 & 0,4 & 0,1 & 0,5 & 2,0 \\
\hline \multirow{2}{*}{$\begin{array}{l}\text { MDL abre oportunidades para outros } \\
\text { tipos de empréstimos }\end{array}$} & $18 \%$ & $23 \%$ & $40 \%$ & $25 \%$ & $65 \%$ & $18 \%$ & $18 \%$ & $35 \%$ & \\
\hline & 0,2 & 0,5 & 0,6 & 0,8 & 1,4 & 0,7 & 0,9 & 1,6 & 3,0 \\
\hline \multirow{2}{*}{$\begin{array}{l}\text { O MDL traz melhorias tecnológicas } \\
\text { para a produção além do benefício } \\
\text { ambiental }\end{array}$} & $36 \%$ & $31 \%$ & $67 \%$ & $18 \%$ & $85 \%$ & $5 \%$ & $10 \%$ & $15 \%$ & \\
\hline & 0,4 & 0,6 & 1,0 & 0,5 & 1,5 & 0,2 & 0,5 & 0,7 & 2,2 \\
\hline \multirow{2}{*}{$\begin{array}{l}\text { Interesse da Matriz estrangeira (caso } \\
\text { haja) }\end{array}$} & $22 \%$ & $11 \%$ & $33 \%$ & $7 \%$ & $41 \%$ & $4 \%$ & $56 \%$ & $59 \%$ & \\
\hline & 0,2 & 0,2 & 0,4 & 0,2 & 0,7 & 0,1 & 2,8 & 2,9 & 3,6 \\
\hline \multirow{2}{*}{$\begin{array}{l}\text { Benefícios socias (exemplo criação } \\
\text { de empregos) }\end{array}$} & $23 \%$ & $13 \%$ & $36 \%$ & $33 \%$ & $69 \%$ & $8 \%$ & $23 \%$ & $31 \%$ & \\
\hline & 0,2 & 0,3 & 0,5 & 1,0 & 1,5 & 0,3 & 1,2 & 1,5 & 2,9 \\
\hline \multirow{2}{*}{ Pressão dos acionistas } & $17 \%$ & $19 \%$ & $36 \%$ & $28 \%$ & $64 \%$ & $8 \%$ & $28 \%$ & $36 \%$ & \\
\hline & 0,2 & 0,4 & 0,6 & 0,8 & 1,4 & 0,3 & 1,4 & 1,7 & 3,1 \\
\hline \multirow{2}{*}{ Movimento social/Mídia } & $25 \%$ & $19 \%$ & $44 \%$ & $17 \%$ & $61 \%$ & $14 \%$ & $25 \%$ & $39 \%$ & \\
\hline & 0,3 & 0,4 & 0,6 & 0,5 & 1,1 & 0,6 & 1,3 & 1,8 & 2,9 \\
\hline \multirow{2}{*}{ Influência/Incentivo do Governo } & $3 \%$ & $18 \%$ & $21 \%$ & $18 \%$ & $39 \%$ & $16 \%$ & $45 \%$ & $61 \%$ & \\
\hline & 0,0 & 0,4 & 0,4 & 0,6 & 0,9 & 0,6 & 2,2 & 2,9 & 3,8 \\
\hline \multirow{2}{*}{$\begin{array}{l}\text { A empresa que sempre teve } \\
\text { interesses de melhorias ambientais }\end{array}$} & $74 \%$ & $21 \%$ & $95 \%$ & $5 \%$ & $100 \%$ & $0 \%$ & $0 \%$ & $0 \%$ & \\
\hline & 0,7 & 0,4 & 1,2 & 0,2 & 1,3 & - & - & - & 1,3 \\
\hline \multirow{2}{*}{$\begin{array}{l}\text { Acompanhar o movimento de } \\
\text { empresas do mesmo setor }\end{array}$} & $23 \%$ & $20 \%$ & $43 \%$ & $14 \%$ & $57 \%$ & $9 \%$ & $34 \%$ & $43 \%$ & \\
\hline & 0,2 & 0,4 & 0,6 & 0,4 & 1,1 & 0,3 & 1,7 & 2,1 & 3,1 \\
\hline \multirow{2}{*}{$\begin{array}{l}\text { Informações em relação ao MDL eram } \\
\text { mais claras do que as dos outros } \\
\text { programas de redução de emissões }\end{array}$} & $14 \%$ & $27 \%$ & $41 \%$ & $14 \%$ & $54 \%$ & $19 \%$ & $27 \%$ & $46 \%$ & \\
\hline & 0,1 & 0,5 & 0,7 & 0,4 & 1,1 & 0,8 & 1,4 & 2,1 & 3,2 \\
\hline
\end{tabular}

- custos de negociação ou elaboração de contratos - são aqueles resultantes da preparação dos documentos anteriores à implantação do projeto, e os consequentes da procura pelo comprador dos créditos de carbono. Como as negociações são feitas em mercado de balcão, sem câmara de compensação, é mais difícil e custoso encontrar compradores para seus certificados. Assim, essa procura incorre em custos de transação.
Os custos ex post são os que podem emergir depois da implantação do projeto de MDL, como custos de monitoramento, custos de adaptação resultantes de mudanças que poderiam ocorrer depois de finalizada a primeira fase de Kyoto (2008 a 2012).

Com base nessa classificação, as análises das alternativas respondidas nos questionários permitiram identificar quais desses custos exercem influências mais significativas tanto 
Tabela 2

\section{Alternativas Referentes à Segunda Questão do Questionário e Percentual de Respostas por Grau de Contribuição em Cada Variável}

\begin{tabular}{|c|c|c|c|c|c|c|c|c|c|}
\hline \multirow{3}{*}{ Perguntas } & \multicolumn{8}{|c|}{ Grau de Contribuição } & \multirow{3}{*}{$\begin{array}{c}\text { Total } \\
\text { Balizado }\end{array}$} \\
\hline & $\begin{array}{l}\text { Muito } \\
\text { (A) }\end{array}$ & $\begin{array}{l}\text { Não Muito } \\
\text { (B) }\end{array}$ & $A+B$ & $\begin{array}{l}\text { Pouco } \\
\text { (C) }\end{array}$ & $A+B+C$ & $\begin{array}{c}\text { Muito } \\
\text { Pouco (D) }\end{array}$ & $\begin{array}{l}\text { Nada } \\
(E)\end{array}$ & $D+E$ & \\
\hline & 1 & 2 & & 3 & & 4 & 5 & & \\
\hline \multirow{2}{*}{ Tecnologia aplicada no projeto } & $26 \%$ & $21 \%$ & $47 \%$ & $13 \%$ & $61 \%$ & $5 \%$ & $34 \%$ & $39 \%$ & \\
\hline & 0,3 & 0,4 & 0,7 & 0,4 & 1,1 & 0,2 & 1,7 & 1,9 & 3,0 \\
\hline \multirow{2}{*}{$\begin{array}{l}\text { Tecnologia de medição das } \\
\text { reduções de emissões }\end{array}$} & $24 \%$ & $16 \%$ & $39 \%$ & $21 \%$ & $61 \%$ & $8 \%$ & $32 \%$ & $39 \%$ & \\
\hline & 0,2 & 0,3 & 0,6 & 0,6 & 1,2 & 0,3 & 1,6 & 1,9 & 3,1 \\
\hline \multirow{2}{*}{$\begin{array}{l}\text { Eficiência da empresa de engenharia } \\
\text { que implantou o projeto }\end{array}$} & $41 \%$ & $14 \%$ & $54 \%$ & $11 \%$ & $65 \%$ & $3 \%$ & $32 \%$ & $35 \%$ & \\
\hline & 0,4 & 0,3 & 0,7 & 0,3 & 1,0 & 0,1 & 1,6 & 1,7 & 2,7 \\
\hline \multirow{2}{*}{ Eficiência da consultoria contratada } & $19 \%$ & $27 \%$ & $46 \%$ & $19 \%$ & $65 \%$ & $3 \%$ & $32 \%$ & $35 \%$ & \\
\hline & 0,2 & 0,5 & 0,7 & 0,6 & 1,3 & 0,1 & 1,6 & 1,7 & 3,0 \\
\hline \multirow{2}{*}{$\begin{array}{l}\text { Eficiência da Entidade Operacional } \\
\text { Designada (EOD) }\end{array}$} & $14 \%$ & $16 \%$ & $30 \%$ & $27 \%$ & $57 \%$ & $11 \%$ & $32 \%$ & $43 \%$ & \\
\hline & 0,1 & 0,3 & 0,5 & 0,8 & 1,3 & 0,4 & 1,6 & 2,1 & 3,3 \\
\hline \multirow{2}{*}{ Tipo/Setor do projeto } & $28 \%$ & $25 \%$ & $53 \%$ & $25 \%$ & $78 \%$ & $6 \%$ & $17 \%$ & $22 \%$ & \\
\hline & 0,3 & 0,5 & 0,8 & 0,8 & 1,5 & 0,2 & 0,8 & 1,1 & 2,6 \\
\hline \multirow{2}{*}{ Escala do projeto } & $24 \%$ & $19 \%$ & $43 \%$ & $19 \%$ & $62 \%$ & $8 \%$ & $30 \%$ & $38 \%$ & \\
\hline & 0,2 & 0,4 & 0,6 & 0,6 & 1,2 & 0,3 & 1,5 & 1,8 & 3,0 \\
\hline \multirow{2}{*}{$\begin{array}{l}\text { Prazo entre entrega do DCP e } \\
\text { monitoramento }\end{array}$} & $8 \%$ & $26 \%$ & $34 \%$ & $24 \%$ & $58 \%$ & $11 \%$ & $32 \%$ & $42 \%$ & \\
\hline & 0,1 & 0,5 & 0,6 & 0,7 & 1,3 & 0,4 & 1,6 & 2,0 & 3,3 \\
\hline \multirow{2}{*}{$\begin{array}{l}\text { Metodologia de linha de base } \\
\text { utilizada }\end{array}$} & $29 \%$ & $16 \%$ & $45 \%$ & $29 \%$ & $74 \%$ & $5 \%$ & $21 \%$ & $26 \%$ & \\
\hline & 0,3 & 0,3 & 0,6 & 0,9 & 1,5 & 0,2 & 1,1 & 1,3 & 2,7 \\
\hline \multirow{2}{*}{$\begin{array}{l}\text { O valor apresentado no DCP foi } \\
\text { superestimado para trabalhar com } \\
\text { margem de segurança }\end{array}$} & $17 \%$ & $14 \%$ & $31 \%$ & $25 \%$ & $56 \%$ & $8 \%$ & $36 \%$ & $44 \%$ & \\
\hline & 0,2 & 0,3 & 0,4 & 0,8 & 1,2 & 0,3 & 1,8 & 2,1 & 3,3 \\
\hline \multirow{2}{*}{ Falta de know-how inicial } & $29 \%$ & $13 \%$ & $42 \%$ & $13 \%$ & $55 \%$ & $16 \%$ & $29 \%$ & $45 \%$ & \\
\hline & 0,3 & 0,3 & 0,6 & 0,4 & 0,9 & 0,6 & 1,4 & 2,1 & 3,0 \\
\hline
\end{tabular}

como barreiras para implantação dos projetos quanto como determinantes da eficiência dos MDL (sucesso de redução).

\subsection{Conclusão geral sobre os projetos brasileiros}

Segundo os entrevistados, primeiramente o que mais importa na hora de implantar um projeto de MDL é o interesse em melhorias ambientais, mas os recursos financeiros decorrentes da venda dos certificados exercem também papel decisivo na decisão de desenvolver um projeto, funcionando como um forte atrativo. Os custos de negociação decorrentes da venda dos créditos de carbono não são muito altos, uma vez que, em geral, os entrevistados não tiveram muitos problemas em encontrar compradores para seus créditos de carbono, e as consultorias contratadas geralmente foram os intermediários entre vendedores e compradores.

Ainda com relação à falta de informação, a maior parte dos entrevistados apontou dificuldades no entendimento do processo do MDL. De fato, é um processo complexo, com vários estágios, muitas organizações envolvidas, repleto de documentos de cunho jurídico internacional, o que dificulta ainda mais o entendimento, sendo necessário muitas vezes contar com o apoio de consultorias privadas.

Em relação às diferenças entre as reduções efetivas e as estimadas, segundo os entrevistados, os custos de transação exercem papel importante na tentativa de explicar as discre- 
Tabela 3

\section{Alternativas Referentes à Terceira Questão do Questionário e Percentual de Respostas por Grau de Contribuição em Cada Variável}

\begin{tabular}{|c|c|c|c|c|c|c|c|c|c|}
\hline \multirow{3}{*}{ Perguntas } & \multicolumn{8}{|c|}{ Grau de Contribuição } & \multirow{3}{*}{$\begin{array}{c}\text { Total } \\
\text { Balizado }\end{array}$} \\
\hline & $\begin{array}{l}\text { Muito } \\
\text { (A) }\end{array}$ & $\begin{array}{l}\text { Não Muito } \\
\text { (B) }\end{array}$ & $A+B$ & $\begin{array}{l}\text { Pouco } \\
\text { (C) }\end{array}$ & $A+B+C$ & $\begin{array}{c}\text { Muito } \\
\text { Pouco (D) } \\
\end{array}$ & $\begin{array}{c}\text { Nada } \\
(\mathrm{E})\end{array}$ & $D+E$ & \\
\hline & 1 & 2 & & 3 & & 4 & 5 & & \\
\hline \multirow{2}{*}{$\begin{array}{l}\text { Elaboração do DCP de maneira } \\
\text { geral }\end{array}$} & $10 \%$ & $31 \%$ & $41 \%$ & $38 \%$ & $79 \%$ & $5 \%$ & $15 \%$ & $21 \%$ & \\
\hline & 0,1 & 0,6 & 0,7 & 1,2 & 1,9 & 0,2 & 0,8 & 1,0 & 2,8 \\
\hline \multirow{2}{*}{$\begin{array}{l}\text { Comprovação da adicionalidade } \\
\text { do projeto }\end{array}$} & $24 \%$ & $32 \%$ & $55 \%$ & $32 \%$ & $87 \%$ & $3 \%$ & $11 \%$ & $13 \%$ & \\
\hline & 0,2 & 0,6 & 0,9 & 0,9 & 1,8 & 0,1 & 0,5 & 0,6 & 2,4 \\
\hline \multirow{2}{*}{$\begin{array}{l}\text { Preenchimento do teste de } \\
\text { adicionalidade }\end{array}$} & $24 \%$ & $26 \%$ & $50 \%$ & $32 \%$ & $82 \%$ & $5 \%$ & $13 \%$ & $18 \%$ & \\
\hline & 0,2 & 0,5 & 0,8 & 0,9 & 1,7 & 0,2 & 0,7 & 0,9 & 2,6 \\
\hline \multirow{2}{*}{$\begin{array}{l}\text { Validação do DCP de maneira } \\
\text { geral }\end{array}$} & $23 \%$ & $38 \%$ & $62 \%$ & $23 \%$ & $85 \%$ & $5 \%$ & $10 \%$ & $15 \%$ & \\
\hline & 0,2 & 0,8 & 1,0 & 0,7 & 1,7 & 0,2 & 0,5 & 0,7 & 2,4 \\
\hline \multirow{2}{*}{$\begin{array}{l}\text { Validação do DCP por problemas } \\
\text { com a Entidade Operacional } \\
\text { Designada (EOD) }\end{array}$} & $23 \%$ & $28 \%$ & $51 \%$ & $26 \%$ & $77 \%$ & $10 \%$ & $13 \%$ & $23 \%$ & \\
\hline & 0,2 & 0,6 & 0,8 & 0,8 & 1,6 & 0,4 & 0,6 & 1,1 & 2,6 \\
\hline \multirow{2}{*}{$\begin{array}{l}\text { Aprovação do DCP de maneira } \\
\text { geral }\end{array}$} & $33 \%$ & $23 \%$ & $56 \%$ & $28 \%$ & $85 \%$ & $5 \%$ & $10 \%$ & $15 \%$ & \\
\hline & 0,3 & 0,5 & 0,8 & 0,8 & 1,6 & 0,2 & 0,5 & 0,7 & 2,4 \\
\hline \multirow{2}{*}{$\begin{array}{l}\text { Aprovação do DCP por } \\
\text { problemas com a Autoridade } \\
\text { Nacional Designada (AND) }\end{array}$} & $28 \%$ & $26 \%$ & $54 \%$ & $23 \%$ & $77 \%$ & $10 \%$ & $13 \%$ & $23 \%$ & \\
\hline & 0,3 & 0,5 & 0,8 & 0,7 & 1,5 & 0,4 & 0,6 & 1,1 & 2,5 \\
\hline \multirow{2}{*}{$\begin{array}{l}\text { Registro do projeto de maneira } \\
\text { geral }\end{array}$} & $41 \%$ & $15 \%$ & $56 \%$ & $26 \%$ & $82 \%$ & $5 \%$ & $13 \%$ & $18 \%$ & \\
\hline & 0,4 & 0,3 & 0,7 & 0,8 & 1,5 & 0,2 & 0,6 & 0,8 & 2,3 \\
\hline \multirow{2}{*}{$\begin{array}{l}\text { Registro do projeto por problemas } \\
\text { de entendimento com o Comitê } \\
\text { Executivo do MDL }\end{array}$} & $23 \%$ & $33 \%$ & $56 \%$ & $18 \%$ & $74 \%$ & $8 \%$ & $18 \%$ & $26 \%$ & \\
\hline & 0,2 & 0,7 & 0,9 & 0,5 & 1,4 & 0,3 & 0,9 & 1,2 & 2,6 \\
\hline \multirow{2}{*}{ Monitoramento do projeto } & $21 \%$ & $21 \%$ & $42 \%$ & $26 \%$ & $68 \%$ & $16 \%$ & $16 \%$ & $32 \%$ & \\
\hline & 0,2 & 0,4 & 0,6 & 0,8 & 1,4 & 0,6 & 0,8 & 1,4 & 2,8 \\
\hline \multirow{2}{*}{ Certificação do projeto } & $23 \%$ & $26 \%$ & $49 \%$ & $23 \%$ & $72 \%$ & $18 \%$ & $10 \%$ & $28 \%$ & \\
\hline & 0,2 & 0,5 & 0,7 & 0,7 & 1,4 & 0,7 & 0,5 & 1,2 & 2,7 \\
\hline \multirow{2}{*}{ Emissão dos certificados } & $21 \%$ & $31 \%$ & $51 \%$ & $15 \%$ & $67 \%$ & $21 \%$ & $13 \%$ & $33 \%$ & \\
\hline & 0,2 & 0,6 & 0,8 & 0,5 & 1,3 & 0,8 & 0,6 & 1,5 & 2,7 \\
\hline \multirow{2}{*}{ Venda dos certificados } & $2 \%$ & $24 \%$ & $27 \%$ & $20 \%$ & $46 \%$ & $24 \%$ & $29 \%$ & $54 \%$ & \\
\hline & 0,0 & 0,5 & 0,5 & 0,6 & 1,1 & 1,0 & 1,5 & 2,4 & 3,5 \\
\hline \multirow{2}{*}{ Consultorias contratadas } & $3 \%$ & $21 \%$ & $24 \%$ & $26 \%$ & $50 \%$ & $26 \%$ & $24 \%$ & $50 \%$ & \\
\hline & 0,0 & 0,4 & 0,4 & 0,8 & 1,2 & 1,1 & 1,2 & 2,2 & 3,5 \\
\hline \multirow{2}{*}{ Legislação Ambiental } & $5 \%$ & $18 \%$ & $23 \%$ & $25 \%$ & $48 \%$ & $15 \%$ & $38 \%$ & $53 \%$ & \\
\hline & 0,1 & 0,4 & 0,4 & 0,8 & 1,2 & 0,6 & 1,9 & 2,5 & 3,6 \\
\hline \multirow{2}{*}{$\begin{array}{l}\text { Obtenção de informações sobre } \\
\text { MDL }\end{array}$} & $5 \%$ & $31 \%$ & $36 \%$ & $26 \%$ & $62 \%$ & $15 \%$ & $23 \%$ & $38 \%$ & \\
\hline & 0,1 & 0,6 & 0,7 & 0,8 & 1,4 & 0,6 & 1,2 & 1,8 & 3,2 \\
\hline
\end{tabular}


Tabela 4

Percentual Total de Respostas da Questão 4 e Valores Balizados

\begin{tabular}{|c|c|c|c|c|c|c|c|c|c|}
\hline \multirow{2}{*}{ Perguntas } & $(0)$ & (1) & $(2)$ & $(0+1+2)$ & $(3)$ & $(4)$ & (5) & $(3+4+5)$ & \multirow{2}{*}{$\begin{array}{c}\text { Total } \\
\text { Balizado }\end{array}$} \\
\hline & 1 & 2 & 3 & & 4 & 5 & 6 & & \\
\hline \multirow{2}{*}{ a. Excesso de burocracia } & $21 \%$ & $0 \%$ & $0 \%$ & $21 \%$ & $16 \%$ & $24 \%$ & $39 \%$ & $79 \%$ & \\
\hline & 0,2 & 0,0 & 0,0 & 0,2 & 0,6 & 1,2 & 2,4 & 4,2 & 4,4 \\
\hline \multirow{2}{*}{ b. Alto custo de implantação } & $21 \%$ & $11 \%$ & $11 \%$ & $42 \%$ & $29 \%$ & $16 \%$ & $13 \%$ & $58 \%$ & \\
\hline & 0,2 & 0,2 & 0,3 & 0,7 & 1,2 & 0,8 & 0,8 & 2,7 & 3,5 \\
\hline \multirow{2}{*}{$\begin{array}{l}\text { c. Alto custo decorrente do ciclo do MDL } \\
\text { (aprovação, certificação, registro etc.) }\end{array}$} & $26 \%$ & $5 \%$ & $18 \%$ & $50 \%$ & $16 \%$ & $24 \%$ & $11 \%$ & $50 \%$ & \\
\hline & 0,3 & 0,1 & 0,6 & 0,9 & 0,6 & 1,2 & 0,6 & 2,4 & 3,4 \\
\hline \multirow{2}{*}{ d. Baixo ganho com as vendas dos CER's } & $26 \%$ & $13 \%$ & $24 \%$ & $63 \%$ & $8 \%$ & $16 \%$ & $13 \%$ & $37 \%$ & \\
\hline & 0,3 & 0,3 & 0,7 & 1,2 & 0,3 & 0,8 & 0,8 & 1,9 & 3,1 \\
\hline \multirow{2}{*}{$\begin{array}{l}\text { e. Dificuldade de importação de tecnologia e } \\
\text { know-how dos países desenvolvidos }\end{array}$} & $54 \%$ & $16 \%$ & $16 \%$ & $86 \%$ & $5 \%$ & $3 \%$ & $5 \%$ & $14 \%$ & \\
\hline & 0,5 & 0,3 & 0,5 & 1,4 & 0,2 & 0,1 & 0,3 & 0,7 & 2,0 \\
\hline \multirow{2}{*}{ f. Dificuldade em vender os CER's } & $53 \%$ & $11 \%$ & $21 \%$ & $84 \%$ & $5 \%$ & $5 \%$ & $5 \%$ & $16 \%$ & \\
\hline & 0,5 & 0,2 & 0,6 & 1,4 & 0,2 & 0,3 & 0,3 & 0,8 & 2,2 \\
\hline \multirow{2}{*}{ g. Falta de financiamento } & $38 \%$ & $8 \%$ & $24 \%$ & $70 \%$ & $19 \%$ & $0 \%$ & $11 \%$ & $30 \%$ & \\
\hline & 0,4 & 0,2 & 0,7 & 1,3 & 0,8 & 0,0 & 0,6 & 1,4 & 2,7 \\
\hline \multirow{2}{*}{$\begin{array}{l}\text { h. Interesse em outras alternativas mais } \\
\text { lucrativas de reduções de emissões }\end{array}$} & $42 \%$ & $21 \%$ & $21 \%$ & $84 \%$ & $8 \%$ & $5 \%$ & $3 \%$ & $16 \%$ & \\
\hline & 0,4 & 0,4 & 0,6 & 1,5 & 0,3 & 0,3 & 0,2 & 0,7 & 2,2 \\
\hline \multirow{2}{*}{$\begin{array}{l}\text { i. Incerteza sobre validade dos CER's pós } \\
2012\end{array}$} & $21 \%$ & $3 \%$ & $24 \%$ & $47 \%$ & $21 \%$ & $18 \%$ & $13 \%$ & $53 \%$ & \\
\hline & 0,2 & 0,1 & 0,7 & 1,0 & 0,8 & 0,9 & 0,8 & 2,6 & 3,5 \\
\hline
\end{tabular}

Nota: Número balizado: medida de cálculo que transforma os valores a uma mesma base (ao número de 1 a 11, no topo de algumas tabelas). 0 número balizado ajuda na comparação vertical dos intervalos de SR. Equivale a uma nota atribuída de 1 a 11 . 0 cálculo é o total de percentual de representação da variável multiplicada pelo número no topo da coluna. Analisar o total balizado significa dizer que, quanto mais próximo de 11, maior o SR e vice-versa.

pâncias encontradas entre os SR, principalmente os custos de informação e os custos de mensuração e monitoramento.

Existe muita insatisfação com as intermediadoras do projeto, como as auditorias, ou a Autoridade Nacional Designada $(\mathrm{AND})^{(5)}$ e até mesmo o próprio Comitê Executivo do MDL. Entrevistados relatam que em alguns casos as Entidades Operacionais Designadas (EODs) ${ }^{(6)}$, na hora de auditar e validar os projetos, acabam atrasando o processo, uma vez que fazem muitas solicitações em diferentes momentos, o que causa mais custos de transação para o proponente, pois os contratos têm de ser refeitos, reavaliados, tomando muito tempo e gerando incertezas para os proponentes. Alguns também sugerem que seja aumentado o número de EODs, pois assim, com maior concorrência, a qualidade do serviço poderia melhorar.

Na mesma linha, os entrevistados demonstram insatisfação em relação à adoção de uma metodologia não adequada, ocasionando, assim, um desenvolvimento insatisfatório do projeto.
Muitas vezes isso ocorre por problemas de falta de informações, o que leva à escolha de uma metodologia inadequada ao tipo do projeto, causando mais custos de transação. É mencionado que alguns cálculos não abrangem todas as variáveis necessárias, como, por exemplo, as alterações climáticas ou especificidades locais dos projetos brasileiros, o que resulta em modelos matemáticos imprecisos. Segundo outro entrevistado, a fórmula de cálculo disponibilizada pela UNFCCC considera que o peso da composição do lixo não condiz com o padrão do lixo brasileiro. Por essa razão, segundo alguns entrevistados, projetos de aterros sanitários apresentam diferenças nos SR. Essa dificuldade de padronização de cálculo e metodologia pode ser extrapolada para outros tipos de projetos, como os agrícolas.

Nessa mesma linha, um entrevistado aponta que existiam metodologias mais claras e menos complexas no passado, mas que, na busca por diminuir oportunismos, algumas regras ficaram mais rígidas, aumentando a complexidade e dificultando o 
Quadro 3

\section{Alternativas do Questionário de Acordo com Classificação de Custos de Transação Ex Ante e Ex Post}

\begin{tabular}{|c|c|c|}
\hline \multirow{17}{*}{ Ex ante } & \multirow{9}{*}{ Custos de Informação } & Informação necessária para se determinar a metodologia de linha de base utilizada \\
\hline & & Obtenção de informações sobre MDL \\
\hline & & Falta de know-how inicial \\
\hline & & Informações sobre como se adequar à legislação ambiental \\
\hline & & $\begin{array}{l}\text { Eficiência da consultoria contratada que pode ser afetada por falta, assimetria ou má } \\
\text { interpretação das informações }\end{array}$ \\
\hline & & $\begin{array}{l}\text { Tecnologia aplicada no projeto que pode ser afetada por falta, assimetria ou má } \\
\text { interpretação das informações }\end{array}$ \\
\hline & & $\begin{array}{l}\text { Eficiência da empresa de engenharia que implantou o projeto, que pode ser afetada por } \\
\text { falta, assimetria ou má interpretação das informações }\end{array}$ \\
\hline & & $\begin{array}{l}\text { Eficiência da consultoria contratada que pode ser afetada por falta, assimetria ou má } \\
\text { interpretação das informações }\end{array}$ \\
\hline & & $\begin{array}{l}\text { Eficiência da Entidade Operacional Designada e da Autoridade Nacional Designada que } \\
\text { podem ser afetadas por falta, assimetria ou má interpretação das informações }\end{array}$ \\
\hline & Custo de Intermediários & $\begin{array}{l}\text { Taxas de serviços pagos a consultorias contratadas, auditorias, e ao Comitê Executivo para } \\
\text { validar, registrar e aprovar os projetos }\end{array}$ \\
\hline & \multirow{3}{*}{ Outros Custos } & $\begin{array}{l}\text { O valor apresentado no DCP foi superestimado para trabalhar com margem de segurança, } \\
\text { podendo gerar gastos de mensuração inadequados }\end{array}$ \\
\hline & & $\begin{array}{l}\text { Prazo entre entrega do DCP e monitoramento, o que pode incorrer em diferenças de } \\
\text { reduções decorrentes de gap entre preparação do DCP e implantação do projeto } \\
\text { efetivo }\end{array}$ \\
\hline & & $\begin{array}{l}\text { Dificuldade de importação de tecnologia e know-how dos países desenvolvidos incorrendo } \\
\text { em gastos em desenvolver tecnologia própria elou levantamento de novos conhecimentos }\end{array}$ \\
\hline & \multirow{4}{*}{$\begin{array}{l}\text { Custos de Negociação } \\
\text { e Elaboração de } \\
\text { Contratos }\end{array}$} & Dificuldade em vender os CER's \\
\hline & & Elaboração do DCP de maneira geral \\
\hline & & Comprovação da adicionalidade do projeto \\
\hline & & Preenchimento do teste de adicionalidade \\
\hline \multirow{5}{*}{ Expost } & \multirow{2}{*}{$\begin{array}{l}\text { Custo de Monitoramento } \\
\text { e Mensuração }\end{array}$} & Tecnologia de medição das reduções de emissões necessária para monitoramento \\
\hline & & Monitoramento do projeto \\
\hline & \multirow{2}{*}{ Custos Administrativos } & Certificação do projeto \\
\hline & & Emissão dos certificados \\
\hline & $\begin{array}{l}\text { Custo de Renegociação } \\
\text { e Redesenho Contratual }\end{array}$ & Incerteza sobre validade dos CER's pós 2012 \\
\hline
\end{tabular}

enquadramento dos projetos. Assim, existem metodologias que são atualizadas constantemente, aumentando progressivamente os custos de transação a cada novo pedido de aprovação. Também foi mencionado que, mesmo quando um MDL já existe e busca apenas a renovação, às vezes, ainda assim, deve adotar outra metodologia diversa daquela que o proponente tinha utilizado, além de ser necessário um alto nível de exigência de comprovação das informações, o que dificulta ainda mais a renovação dos projetos.

Em relação à legislação ambiental, apesar de ser uma etapa bastante complexa e cheia de requisitos para aprovação, de acordo com a maioria dos proponentes, esta não criou muitos problemas para a implantação de um MDL. As consultorias também não constituem grande impeditivo e, de maneira geral, 
somente uma pequena parte dos entrevistados considera que elas dificultam a implantação do MDL.

Outra razão que aparece com um peso elevado de respostas resulta da insegurança a respeito do que irá acontecer com o futuro do MDL, e se haverá compradores para os certificados resultantes das reduções de emissões futuras, custos de transação ex post ao projeto.

Outra grande reclamação apontada refere-se aos custos do projeto, tanto os diretamente ligados à produção, como problemas decorrentes da tecnologia empregada, com a empresa de engenharia, e também com os custos de transação decorrentes dos gastos diretamente efetuados com as organizações, como taxas de registro e de auditoria. Muitas vezes, esses custos superam até mesmo o ganho com a venda dos certificados, o que inviabiliza a implantação de um projeto de MDL.

Concluindo, os custos de transação fazem parte do ciclo do MDL e podem atuar como barreiras para novos MDL, pois estão presentes desde a elaboração de contratos, levantamento de informações, monitoramento, negociações e demais gastos resultantes do arcabouço institucional que dá sustentação às relações entre as organizações existentes e as normas necessárias ao andamento do MDL. Os custos de transação também afetam o sucesso de redução dos projetos, principalmente os resultantes de assimetria de informações e problemas de mensuração dos cálculos de estimativas.

A UNFCCC está atenta à diminuição dos custos de transação. O Comitê Executivo do MDL, por exemplo, criou o MDL programático, por meio do qual diversos proponentes podem fazer apenas um pedido junto ao Comitê, não sendo necessário um processo para cada interessado, bastando haver características comuns e entrarem com um pedido geral. Essa é uma grande ferramenta que, embora incipiente, está sendo bastante discutida nas reuniões do MDL. Outra atitude do Comitê do MDL são as discussões constantes, por meio das reuniões trimestrais do MDL a respeito de simplificação e consolidação das metodologias. Outros fatores que poderiam diminuir os custos seriam as melhorias de relacionamento entre proponentes e organizações, a redução de taxas referentes ao processo e a maior disseminação de informações.

\section{CONCLUSÃO}

A conscientização maior dos países em relação ao aumento da concentração dos GEE na atmosfera desencadeou a criação do Protocolo de Kyoto como tentativa de minimizar as emissões excessivas dos gases. A princípio, sua criação já foi um avanço, independentemente de os objetivos propostos serem alcançados ou de suas metas não serem muito agressivas. Kyoto sinaliza antes uma consciência global no sentido de que algo deve ser feito para mitigar as mudanças climáticas e não apenas uma tentativa de alteração de atitudes de uma minoria interessada.

O entendimento do Protocolo, bem como de suas atualizações, é tarefa bastante complexa, uma vez que se trata de documentos que utilizam linguagem de natureza técnica baseada no entendimento jurídico internacional. Suas regras nem sempre são objetivas e, em alguns pontos, caracterizadas pela ausência de definições claras e unívocas, o que provoca críticas e discussões que ocorrem desde sua criação até os dias de hoje. Isso foi comprovado neste trabalho, uma vez que a dificuldade em obter informações sobre o MDL é constantemente apontada pelos entrevistados na pesquisa. No entanto, deve ser enfatizado que o Protocolo é um acordo que pressupõe a possibilidade de alterações na busca de melhorias e, segundo suas premissas, por meio do aprendizado contínuo, espera-se que os erros sejam reduzidos para tornar todo o processo mais eficiente e adaptado à realidade.

A complexidade de Kyoto e, consequentemente, do Mecanismo de Desenvolvimento Limpo resulta de uma série de instituições e organizações responsáveis por seu desenvolvimento. Ao mesmo tempo em que é necessário um aparato institucional para evitar oportunismos e falhas de procedimentos de implantação de um MDL, o excesso de normas e de organizações acaba dificultando a implantação de novos projetos. Assim, surgem os custos de transação inerentes a todas as etapas do ciclo do projeto, que podem afetar a eficiência de um projeto e influenciar a decisão de um proponente em implantar um MDL.

Em relação ao panorama mundial de distribuição dos projetos de MDL, os países com maior número de MDLs são Índia, China e Brasil. Quando analisado o total de certificados emitidos, essa classificação se altera, e os países com maior volume reduzido são China, Índia, Coreia do Sul e Brasil. Os setores mais relevantes em termos de volume de redução de emissões são $\mathrm{HFC}, \mathrm{N} 2 \mathrm{O}$ e, quando analisado o número de projetos, o setor de biomassa é o primeiro, seguido por energia hidrelétrica e energia eólica. Os projetos agrícolas têm uma participação de $8 \%$ em número de projetos, estando entre os dez setores com maior quantidade de projetos de MDL. A participação não é tão relevante, pois existem setores com uma concentração grande de projetos. Em termos de volume, o setor agrícola detém apenas $1 \%$, principalmente por causa dos projetos com alto potencial de redução de HFC e NO2.

Ao considerar o desempenho do MDL (sucesso de redução) em número de projetos, a maioria dos MDLs não cumpriu a estimativa de redução. No entanto, em termos de volume de reduções de emissões, a maioria dos projetos cumpriu mais de $91 \%$ do SR.

Os setores agrícolas, tanto os mundiais quanto os brasileiros, são os com menores percentuais de sucesso de redução; assim, os setores menos eficientes são os de resíduos sólidos e agricultura (no Brasil, agricultura e resíduos sólidos). Pode-se levantar a hipótese de que essas diferenças ocorrem em razão de problemas com metodologia de cálculo que afetam as projeções de reduções.

Com base nas análises das respostas dos entrevistados dos projetos brasileiros de MDL, conclui-se que, como o ciclo do 
MDL é composto de diversas etapas, entremeadas por organizações e normas específicas, podem ocorrer falhas de informação que desencadeiam problemas de cálculos, ineficiências das entidades intermediárias, além de negociações inadequadas. Os custos também podem atuar como barreiras para novos MDL, estando presentes desde a elaboração de contratos, o levantamento de informações, o monitoramento, as negociações e demais gastos resultantes do arcabouço institucional que dá sustentação às relações entre as organizações existentes e as normas necessárias ao andamento do MDL. Os custos de transação analisados neste trabalho, tanto os ex ante quanto os ex post (WILLIAMSON, 1985; 1993), afetam o sucesso de redução dos MDLs brasileiros e são barreiras ao crescimento desse mercado de carbono. Os mais relevantes são os ex ante, basicamente os decorrentes de falta ou falhas de informações e os de mensuração e monitoramento.
(1) Crédito de carbono, certificado de carbono, certificado de redução de emissão, essa é a nomenclatura utilizada no projeto para designar genericamente os certificados resultantes das reduções de emissão dos $\mathrm{CO}_{2} \mathrm{e}$, englobando reduções certificadas de emissões (RCE) do Mecanismo de Desenvolvimento Limpo (MDL) e os demais certificados de redução de emissões resultantes de outros mercados.

(2) Bem livre é aquele cuja oferta é ilimitada, pode ser consumido sem custos e, por isso mesmo, não é passível de apropriação privada.

(3) O Comitê Executivo do MDL foi constituído para supervisionar o processo do MDL e tem a função de tornar públicas as informações sobre as atividades de projeto de MDL, promover a emissão dos certificados, dentre outras funções.

(4) A base de dados dos projetos está disponível no site da UNFCCC (2010) e no da Unep Risoe (2009).

(5) A Autoridade Nacional Designada (AND) é definida pelo país em desenvolvimento que pretende hospedar um projeto de MDL. Seu objetivo principal é aprovar ou não os projetos, analisando sua contribuição para o desenvolvimento sustentável, e verificar se as demais premissas estão sendo cumpridas.

(6) A Entidade Operacional Designada (EOD) é uma entidade jurídica (nacional ou internacional), credenciada pelo Comitê Executivo do MDL e que faz a validação, a verificação e a certificação da atividade do projeto.
CHADWICK, Bruce. Transaction costs and the clean development mechanism. Natural Resource Forum, v.30, n.4, p.256-271, Nov. 2006. [DOI: 10.1111/j.1477-8947.2006.00126.x].

CHANDER, Parkash; TULKENS, Henry. Cooperation, stability and self-enforcement in international environmental agreements: a conceptual discussion. Paper prepared for the David Bradford Memorial Conference. Venice Summer Institute. San Servolo, Munich. July 23, 2006.

COASE, R.H. The problem of social cost. Journal of Law and Economics, University of Virginia, v.3, p.1-44, Oct. 1960.

CONVENÇÃO-QUADRO DAS NAÇÕES UNIDAS SOBRE MUDANÇA DE CLIMA - CQNUMC. Protocolo de Kyoto à Convenção sobre Mudança do Clima, 1997. Editado e traduzido pelo Ministério da Ciência e Tecnologia (MCT) com 0 apoio do Ministério das Relações Exteriores. Disponível em: <www.mct.gov.br/clima/quioto/protocolo.htm>. Acesso em: Nov. 2004a.

CONVENÇÃO-QUADRO DAS NAÇÕES UNIDAS SOBRE MUDANÇA DE CLIMA - CQNUMC. Quadro das Nações
Unidas sobre mudança do clima. Publicado pela Unidade de Informações sobre Mudança do Clima (PNUMA) (IUC) em nome do Secretariado Permanente da Convenção. Editado e traduzido pelo Ministério da Ciência e Tecnologia (MCT) com o apoio do Ministério das Relações Exteriores. Disponível em: <www.mct.gov.br/clima/convencao.htm>. Acesso em: Nov. 2004b.

GODOY, Sara Gurfinkel M. Uma análise do mercado mundial de certificados de carbono. Revista de Pós-Graduação em Ciências Socias da UFRN, Cronos, Natal, Universidade Federal do Rio Grande do Norte, v.10, n.2, p.77-99, jul./dez. 2009.

GODOY, Sara Gurfinkel M. Protocolo de Kyoto e os países em desenvolvimento: uma avaliação da utilização do mecanismo de desenvolvimento limpo. 2010. Tese (Doutorado) - Programa de Pós-Graduação em Ciência Ambiental (PROCAM) da Universidade de São Paulo, São Paulo, São Paulo, Brasil, 2010.

MUELLER, C.C. Políticas sugeridas pela teoria neoclássica da poluição. Brasília, 2002. Mimeografado. 


NORTH, D. Institutions, institutional change and economic
performance. Cambridge: Press Syndicate of the University
of Cambridge, 1990. p.1-106.
[DOI: 10.1017/CBO9780511808678].
NORTH, D. Custos de transação, instituições e desempenho
econômico. Rio de Janeiro: Instituto Liberal, 1994.
NORTH, D.Understanding the process of economic change.
Princeton: University Press, 2005.
PIGOU, A.C. The economics of welfare. London: McMillan,
1920.
PINDYCK, R.S.; RUBINFIELD, D.L. Microeconomia. 4.ed.
São Paulo: Makron Books, 1999.
UNEP RISOE. Centre on Energy, Climate and Sustainable
Development (URC). CDM Pipeline overview. 2009.
Disponível em: <www.uneprisoe.org/>. Acesso em: Mar. 2009.
UNITED NATIONS FRAMEWORK CONVENTION ON
CLIMATE CHANGE (UNFCCC). Different documents.

Disponivel em: <cdm.unfccc.int>. Acesso em: Feb. 2010.

WILLIAMSON, O.E. The economics institutions of capitalism. New York: The Free Press, 1985. 445p.

WILLIAMSON, O.E. Transaction cost economics and organization theory institutional and corporate change, v.2 n.2, p.107-156, 1993.
ZYLBERSZTAJN, D. Estruturas de governança e coordenação do agribusiness: uma aplicação da Nova Economia das Instituições. 1995. 238p. Tese (Livre-Docência) - Departamento de Administração da Faculdade de Economia, Administração e Contabilidade da Universidade de São Paulo, São Paulo, São Paulo, Brasil, 1995.

ZYLBERSZTAJN, D.; SZTAJN, R. A economia e o direito de propriedade. Revista de Direito Mercantil, Industrial, Econômico e Financeiro, São Paulo, Faculdade de Direito da USP, v.126, p.112-116, abr./maio/jun. 2002.

\section{Projects to reduce greenhouse gas emissions: performance and transaction costs}

Based on the new institutional economics, the focus of this research was to identify transaction costs in CDM (Clean Development Mechanism) projects and investigate whether they affect project efficiency or create project development barriers. More specifically, this study analyzed the variables that could affect the differences between estimated emissions reduction of CDM projects and the actual reductions obtained (Reduction Success - RS) after the project has been implemented and monitored, verifying if agricultural projects are more or less efficient. Most projects do not show satisfactory performance in terms of RS, even though most achieve more than $91 \%$ RS. The most efficient sectors in the world are HFC and N2O (in Brazil, N2O and fossil fuel), and the least efficient sectors are solid waste and agriculture (in Brazil, agriculture and solid waste). Finally, this study concludes that transaction costs affect the success of CDM reductions, the most relevant being ex-ante costs resulting from information gaps and measurement problems.

Keywords: clean development mechanism, institutional economics, institutions, new institutional economics, carbon credit, Kyoto Protocol, carbon market.

\section{Proyectos de reducción de emisiones de gases de efecto invernadero: desempeño y costos de transacción}

Con base en la nueva economía institucional, el objeto de este estudio fue identificar los costos de transacción existentes en los proyectos de mecanismo de desarrollo limpio (MDL) e investigar si dichos costos impiden su desarrollo y si pueden, además, afectar la eficiencia de los proyectos ya implementados. Más concretamente, se analizaron las variables que inciden en las diferencias entre las reducciones de emisiones estimadas en los proyectos de MDL y las reducciones efectivamente verificadas (éxito de reducción - ER) tras la implementación y seguimiento del proyecto. De esa manera, se pudo verificar si los proyectos agrícolas son más o menos eficientes. Con relación al ER, la mayor parte de los proyectos no presenta un desempeño satisfactorio. Sin embargo, en lo que concierne al volumen de reducciones, la mayoría cumple con más del 91\% de ER. Los sectores mundiales más eficientes en Brasil son N2O y sustitución de energía fósil, y los sectores de agricultura y residuos sólidos son los menos eficientes. Se concluye que los costos de transacción afectan el éxito de las reducciones de MDL. Entre ellos, los más importantes son los costos ex ante, que resultan de problemas relativos a la falta de información y problemas de medición.

Palabras clave: mecanismo de desarrollo limpio, nueva economía institucional, economía institucional, Protocolo de Kyoto, costos de transacción, mercado de carbono, créditos de carbono. 